\title{
Female Protagonist in Libyan Short Story Post the Arab Spring: A Critical Discourse Analysis
}

\author{
Dr. Safa Elnaili \\ Assistant Professor of Arabic \\ Department of Modern Languages \& Classics \\ The University of Alabama \\ Tuscaloosa, AL 35487, USA
}

\begin{abstract}
The Arab Spring, no doubt, brought socio-political changes that re-shaped, and continue to shape, society and its cultural attitudes. The volume of literary production increased following the Libyan uprising in 2011 to reflect on these political reforms and social changes. This paper investigates how Libyan women are represented in literary texts through the female protagonist post the Arab Spring. The study implements critical discourse analysis to critically analyze how gender stereotypes are reproduced through language use within sociopolitical context. The paper analyzes several Libyan short stories written by male and female authors, providing an analytical reading of female representation post the Libyan uprising.
\end{abstract}

Keywords: Critical Discourse Analysis, Libyan Literature, Arab Spring.

\section{Introduction}

As a country that had been under colonization and dictatorship for over 100 years, Libyan society suffered sociopolitical turbulence and insecurity that lead to cultural damage. There is no doubt that this socio-cultural instability was, to a large extent, revealed in literary works especially in short stories ${ }^{1}$. According to Fagih (2008), the leading character in Libyan short stories is mostly a simple man struggling daily to survive hardship and oppression. Alhaddad (2010) points that the image of women in literary works is mostly negative; they are pictured as helpless woman suffering social inequality. The vulnerability of the female protagonist in the face of political oppression and/or social injustice, is strongly presented in Libyan modern literature especially throughout the era of Qaddafi`s role. After the spark of the Arab Spring, and "as state media and censorship became nearly obsolete in free Libya, many publications sprang up." (Gheblawi, 2012, para.20)bringing many Libyan writers to the forefront of the Libyan revolution. A great number of writings were published in local publication houses and some online. Most of the literary works in the first months of the revolution had revolutionary sentiments. Other works reflected Qaddafi`s oppressive regime. The adaptation to the new reality encouraged writers to write about the fight against the emergence of social and political injustice. (Gheblawi, 2012)

This paper investigates how Libyan women are represented in literary texts through the female protagonist post the Arab Spring. The study implements critical discourse analysis to critically analyze how gender stereotypes are reproduced through language use within sociopolitical context. A number of short stories by different Libyan writers, male and female, are analyzed. The purpose of this research is to diagnose and provide a socio-political perspective on how gender stereotypes are recreated and reproduced in literary text post the Arab Spring.

\section{Libyan Women Post the Arab Spring}

Despite being allowed equal status as men in labor and financial independence, Libyan women suffered under Qaddafi`s civil rights` restrictions, especially in the types of education women could access. They were also excluded from political and economic participation and leadership.

\footnotetext{
${ }^{1}$ Most of Libyan storywriters devoted their time and effort entirely to writing short stories rather than novels and plays due to the lack of literary traditions and well- established/ publishing institutions.
} 
The traditional family law also discriminated women in areas of child custody, marriage, divorce, and domestic violence. The 2011 popular uprise, unfortunately, did not bring change. Although women played a significant role in the uprise, such as, marching in the streets next to men, taking media platforms to lead political movements, they are still underrepresented in official institutions and still lack access to major political roles. Perhaps political change does not have an effect for the fact that social traditions do not yet cope with such change; And as a result, Libyan women remain prisoners of the traditional law in a male society.

\section{The Representation of the Female Protagonist in Libyan Short Story post the Arab Spring}

Although this paper discusses the representation of women in Libyan short story post Libya s Arab Spring in 2011 , it is worth shedding light briefly on the image of the female protagonist before that period, not as a comparison, but rather as context for discussion on how social injustice is reproduced in literary production despite political change. Very few studies have been conducted to analyze and/or describe the protagonist in Libyan literature. A recent study on the connotative meanings of colors in Libyan short stories indicated that the protagonist in general is mostly described in a culturally negative way, the protagonist is usually imaged as weak and stripped of power in the face of the antagonist's force, and in some stories, we even see him/her presented as unworthy (Elnaili, 2014).

Women were not immune of such negative representations. The female protagonist is mostly marginalized in short stories as a reflection of her unjust social status in the Libyan community. We see her emotionally and physiologically abused, for example, we see her in The Yellow Rock by Saleh Saad Youn is negatively presented as unworthy and intelligently undermined: "What a nightmare!' said a woman with an ugly face, an ugly name and a loud tongue" (Chorin, 2008, p. 63), or physically abused in She and the Dogs by Ibrahim El-Kouni where the protagonist Laila is harassed by men in the streets at night on her way home from work: "Cars raced past her, the drivers of them blinking their lights, braking, then stinging her with their glances _ their eyes gleaming like flame, stabbing her like needles, prickling her skin, seeking her nakedness" (Fagih, 2008, p. 51). As she seeks refuge at a store, the owner harasses her with his words and stares; Even when she seeks help from a police officer, she faces the same fate. After a long night and as she finally gets home, she feels as if she had lost part of her to those voices in the dark "She was sensitive to the fact that she had lost something for the first time...lost something important... a legendary wall had crumbled and fell somewhere deep within her" (Fagih, 2008, p. 56).

With the Arab Spring Libyan women are now calling for social justice, and as female activists are battling fearlessly for their rights in the political arenas, it is worth examining whether the female protagonist is battling the same social fight in literary works, and whether gender stereotypes continue to re-exist.

\subsection{CDA and The Post Arab Spring Context}

Van Dijk (2001) defines critical discourse analysis CDA as "a type of discourse analytical research that primarily studies the way social power abuse, dominance, and inequality are enacted, reproduced, and resisted by text and talk in the social and political context." (Van Dijk, 2001, p.352), he goes on by arguing that CDA focuses on how "discourse structures enact, confirm, legitimate, reproduce, or challenge relations of power and dominate in society" (Van Dijk, 2001, p.353). He argues that social and political conflict can be reproduced and even enhanced by representing Others in a negative and demonized way. Van Dijk, in his studies uses lexical descriptions and text structure as analytical tools to investigate and underline these representations. It is thus convenient for this study to implement CDA in analyzing literary texts to underline how women are rerepresented in the social and political discourse of the Arab Spring. The analysis will help understand how sociopolitical injustice can be reinforced through venues other than political and media texts, in this discussion, literary platforms. It will also shed light on the fact that social stereotypes can be reproduced, not only by those in power as Van Dijk points out, but also subconsciously by those aiming to make the change.

\subsection{Libyan Short Stories Post the Arab Spring}

After the popular movement erupted in 2011, Libyan writers were inspired to help change the country to the best. At first their contribution was political "At least a dozen of them detained and tortured by the Gaddafi regime because of their involvement in demonstrations and their reporting about the situation in Libya to the media." [Gheblawi, 2012, para.21], then with censorship becoming nearly obsolete, massive amounts of writings were published all different in type and size: printed or online, articles or tweets. Literary writers engaged in the new discourse and reflected on the various changes that the country was undergoing. Most of the literary works produced during the early months of the revolution had heavy revolutionary sentiments. 
Writers like Azza Al-Maghour described the fights and the bloody battles of the young and the old against the oppressed regime. The unrest in Libya was forcing most writers to devote their time and effort in political writings. They wrote journal articles to give immediate responses to the current critical situation in the country, therefore, the volume of creative writing was growing slow ${ }^{2}$. With the increasing tension and division in the state, Libyan writers have found themselves, once again, standing on shaking grounds. However, several short stories were published after 2011, most of which were published especially online.

\section{Analyzing the Stories}

This paper focuses on short stories published post the Libyan revolution in 2011, most of the stories selected for analysis were published recently in 2017, most of which were published online through a Libyan website named Libya Almostakbal ${ }^{3}$. It is a very active and widely read website by many Libyans and Arabs. For this paper, 15 short stories were selected for discussion. These stories had female protagonists and/or carried representations of women in the narrative through other characters. The discussion of these stories will be through the position of the female character in the narrative in relation to family members, society, and socio-political context.Three themes, according to the researcher's reading, underline the narratives and the discourse women are represented in. These themes portray the social pressures on women in the Libyan community, such as, the pressure of the male figure in the family, traditions of the society, and the war.

\subsection{The Male Dominance}

The Libyan society is a male society, women are brought up in the shade of their fathers, then after marriage, move under the protection of their husbands; This as a result, binds a woman`s faith to the male figure in her family. In the stories she is merely the mother, the wife, the daughter, and the grandmother. The context in which she is placed in the short stories is almost always a social/family context. The authority of the male character is strongly present and unresisted by the female character; for example, inThe Pigeons are not for Sale by Ghalia Younis, the husband refuses his wife's plead to flee the house under the bombards of the war against radical militias in Benghazi, his excuse is the safety of his pigeons that he relied on as the family business and only income. His wife dies from a sniper's bullet leaving the husband in sorrow and regret. In another story by the same author titled Assassination, the wife`s death is an emotional one. As she walks in the hospital room where her husband lies sick, thinking of the many years she sacrificed for him, finds her husband flirting with the young nurse. Younis ends the story with her protagonist in tears "the tears from her eyes spoke to him that he was dead to her." (Younis, 2017, para.1). Azza Al Maghour also underlines the degrading of women by their husbands in The Tea Cup. She points out how Libyan society continues to practice social injustice against women. This is seen through pressing the urge for polygamy or replacing the deceased wife with a new bride. Al Maghour in her story reflects on men's disloyalty to their wife`s memories. The protagonist in The Tea Cupdied of illness after devoting her years to her critical and demanding husband, and who in return, seeks for a new bride at his wife`s funeral.

Women in literary texts post the Arab Spring are seen unfit to make decisions. The leading role in the family, is mostly a "man's" role as implied in Younis' My Wife is an Ominous Crow". The story opens with the husband confessing "I never approved my friend Kamal`s opinion about women being ominous creatures... until my wife proved otherwise." (Younis, 2017, para.1), then as the story goes, he regrets approving his wife`s decision to host his brother in their house. His brother's family moves in for several months, thisforced the husband to spend all his fortune to support two families in his household. Eventually, the husband finds himself broke when his brother takes advantage of his own saving to by the house. Younis ends the story with the husband s final confession: "Didn't I tell you that my wife is an ominous crow? Wasn't it she who "cawed" about this in the first place?!" (Younis, 2017, para.19). Khairia Fathi Abduljaleeladds another example of the negligence of women`s opinions in The Road. The female protagonist takes a cab ride in the new city and as she tries to enjoy the ride and the city

\footnotetext{
${ }^{2} \mathrm{My}$ argument here is supported with statements by several Libyan writers such as Saleh Saad Younis, Mohammed AlMaghboub, \&RejebAsheltami and whom I've communicated with personally.

${ }^{3}$ Libya Almostakbal is an independent media platform that was founded in 2003 by Libyan journalist Hassan Muhammad AlAmin. The website publishes political articles and news reports concerning Libya. It also serves as a platform for literary publication for many creative writers in Libya.

${ }^{4}$ Crows in Arabic and Islamic culture connote pessimism and bad luck. The title is an indication of how men perceive women as bad decision makers and who bring misfortune.
} 
lights, the male driver speeds despite her constant request for him to slow down. The male driver and his action symbolizes leadership and gender superiority in Libyan society.

\subsection{Crushed by Traditions}

Social law in Libyan society is very powerful; Libyans cherish their traditions and consider them very sacred. However, these traditions are unjustifiably harsh on women and contradict women`s rights in Islam. Despite calls for equality and cultural change, women constantly carry the heavy weight of "What will people say?". Authors of our selected stories for this paper present the female protagonist through the lens of traditions. They show how demands for social prestige, financial status, and gender rights are still challenged and reconstructed in the new sociopolitical context of the Arab Spring.Women`s right for a more liberating life style is constantly governed by unjust traditions. For example, in Wrinkles, Laila Al Moghrabinarrates her protagonist's inner battle against aging. The protagonist is displeased with the wrinkles shown in her picture, Al Moghrabi channels to us her protagonist's inner voice to love herself and embrace her age, however, she is defeated by society"s "self-image" culture and buys the most expensive beauty products to cover her wrinkles. Social judgment is also tied to how women are perceived by men; In TheFortune Teller Khairia Fathi Abduljaleel highlights social pressure on woman in marriage. Her protagonist seeks a fortune teller for help in getting a husband, this desperation, as shown through the character, is manifested by negative judgement on unmarried women. The author, in the voice of her character, grows exhausted, hopeless, and walks away with a heavy weight on her heart. This image portrays the female protagonist as weak, dependent, and socially imperfect.

Although financial support is usually the man`s responsibility in a Libyan household, financial status of the family is sometimes linked to a woman`s image as the housewife.A dispute between a husband and his wife takes place in TheSoup Pot byLaila Al Moghrabi, the wife argues with her husband about the shopping list she prepared for Ramadan. Her husband refuses to pay for all the items in the list, especially for a new soup pot. She leaves the house and asks for divorce. The female character in the story may appear a shallow one, however, it shows how housewives have become victims of social appearances. A household that is fully furnished, a kitchen that is fully equipped, and a backyard that is beautifully gardened represent a household of a successful wife and a sociallyaccepted woman. Another example of household responsibility and social image of woman can be found in Baghdad, September 1984. Mahboba Khalifa in this story reflects the agony of housewives towards housekeeping. She shares her memories of her visit to Baghdad, starting a new life away from home, blending in, raising her kids, and the heavy housework she endeavored throughout her stay. The story reveals the heavy duties woman endure alone in their household: "What a torture! ... endless wiping and dusting... my hands are soar" (Khalifa, 2017, para.4). These examples demonstrate the continuous ill-imaged representation of women in social context and underline the legacy of female disempowerment post the sociopolitical movement.

\subsection{Victim of War}

The civil war that followed the Arab Spring in Libya was a destructive one. Many lives were lost: men, children, and women. As many short stories were published after the uprise celebrating the heroes who fought Qaddafi`s tyranny, the great contributions of women in the fight for a better Libya remains invisible. The narratives with the war discourse show women merely as victims of the fight between the militias. Salwa Bin Shatwan tells the story of Grandmother Salha and the misery of the war in Benghazi. Grandmother Salha is a victim of war before and even after her death. Her protagonist is first portrayed as a victim of illiteracy: "She believes that Makkah is in Libya because, according to her, Libya is the whole world and there is no other world that exists beyond Libya" (Bin Shatwan, 2011, para.8), then seen through the eyes of the oppressor as unworthy: "those like grandmother Salha need only one bullet worth 3 dollars to wipe them off the face of earth... they will not hesitate to crush her like a locust rather than respect her as a grandmother" (Bin Shatwan, 2011, para.3). When death finally took grandmother Salha`s life and after she was brought to the hospital, the medical examiner couldn 't provide her son with a legal death certificate for her burial. The political unrest in the country put all paper works on hold till the end of the war, and that date was of course unknown. Bin Shatwan keeps grandmother Salha suspended between the living and the dead in a hospital fridge with a mourning son. The political conflict deprived the female character of a simple human right, a burial. Salah Elhaddad, in a similar example, paints a tragic image of a pregnant women lying dead of bullet shot by the male citizens who were celebrating the rebels' victory in Entrapment. 
Ibrahim Al Faqih sheds light on another form of female victimization in The Beautiful and the Foreseen Fire : sexual abuse in war. His story isof a beautiful lady named Kamilia who made a vow to herself that only a hero is worthy of her beauty. During the revolution she decides to marry a rebel who was known for his bravery in battle. Al Fagih describes this rebel as a 'promising knight'. Despite that rebel's unappealing features, Kamilia saw him as a hero worthy of her love and devotion. However, her vow caused her misery and pain. The ugly rebel was soon hospitalized and his true self surfaced, he was unkind, barbaric, unexperienced in marital relationships, insensitive, and cruel. Yet she remained his loyal and devoted wife: "sometimes, she would rush to the restroom to vomit due to his cruel sexual practices in bed, yet she would consider her tolerance the as a sacrifice"(Al Fagih, 2015, para.14). The protagonist's prison in her marriage is seen as her obligation and destiny for the fact that she is just a woman married to a war hero. From the above discussion, the negative image of women is clearly reproduced in literary texts post Libya`s Arab Spring.

\section{Conclusion}

Despite the political change in the country and the important role women played in the Libyan popular uprise in 2011.Their image in literary production is still a weak one. These post Arab Spring literary works, in general, either celebrated heroic achievements of the Libyan rebels during the first year or discussed the socio-political aftermath of the revolution. The short stories gathered from Almostakbal webpage mostly had male protagonist, whereas the female protagonist led a small number of stories. These stories, unfortunately, do not reflect the feminine contribution in the Libyan revolution. They mostly channel the social injustice practiced against women in society. Therefore, we see women portrayed as weak, marginalized, and deprived of simple rights. The discussed stories were analyzed through three main themes. These themes, according to the researcher, are the most common discourses of women representations in the stories. As their reality, Libyan women in post Arab Spring literary works continue to suffer social inequality by male figures in the family and the traditions in the society, as well as being victims of the very same uprise they participated in alongside the men. From this one can conclude that despite political reform, social traditions in the Libyan community remain unaffected. Political and social discrimination against women are reproduced in literary arenas. The social discourse of women in literary production has not changed, the representations are solely focused on the negative aspects, leaving out the positive roles of women in their communities. It is worth pointing out that in order to employ gender justice, literary works, especially written by female authors, need to also shed light on the great contributions of women in the Libyan society, women discourse in Libyan literature needs its own revolution. Libyan authors need to rethink their approach to women representation by discussing both the negative and the positive in parallel. And as Libyan writer and critic Najat Agila discussed in her critical article on a Libyan drama TV show: "We deeply hope that writers would bring justice to Libyan women... and take in account the development of women 's role in society especially in the areas of education and workforce." (Agila, 2017, para.13).

\section{References}

Abduljaleel, K, F. (2017, June). The Road. Libya Almostakbal. Retrieved from http://www.libya-al-mostakbal.org/89/25491/\%D8\%A7\%D9\%84\%D8\%B7\%D8\%B1\%D9\%8A\%D9\%82\%D9\%82\%D8\%B5\%D8\%A9-\%D8\%AE\%D9\%8A\%D8\%B1\%D9\%8A\%D8\%A9$\% \mathrm{D} 9 \% 81 \% \mathrm{D} 8 \% \mathrm{AA} \% \mathrm{D} 8 \% \mathrm{AD} \% \mathrm{D} 9 \% 8 \mathrm{~A}-\% \mathrm{D} 8 \% \mathrm{~B} 9 \% \mathrm{D} 8 \% \mathrm{~A} 8 \% \mathrm{D} 8 \% \mathrm{AF}-$ \%D8\%A7\%D9\%84\%D8\%AC\%D9\%84\%D9\%8A\%D9\%84.html

Abduljaleel, K, F. (2017, July). The Fortune Teller. Libya Almostakbal. Retrieved from http://www.libya-al-mostakbal.org/89/26413/\%D8\%B9\%D8\%B1\%D8\%A7\%D9\%81\%D8\%A9\%D9\%82\%D8\%B5\%D8\%A9-\%D8\%AE\%D9\%8A\%D8\%B1\%D9\%8A\%D8\%A9$\% \mathrm{D} 9 \% 81 \% \mathrm{D} 8 \% \mathrm{AA} \% \mathrm{D} 8 \% \mathrm{AD} \% \mathrm{D} 9 \% 8 \mathrm{~A}-\% \mathrm{D} 8 \% \mathrm{~B} 9 \% \mathrm{D} 8 \% \mathrm{~A} 8 \% \mathrm{D} 8 \% \mathrm{AF}-$ $\% \mathrm{D} 8 \% \mathrm{~A} 7 \% \mathrm{D} 9 \% 84 \% \mathrm{D} 8 \% \mathrm{AC} \% \mathrm{D} 9 \% 84 \% \mathrm{D} 9 \% 8 \mathrm{~A} \% \mathrm{D} 9 \% 84 . \mathrm{html}$

Abrams, M.H. (1985). A Glossary of Literary Terms. Orlando:Holt, Rinehart and Winston. Agila, N.(2017, July). The Image of Women in Drama...'Rubric' The Secret of Life. Libya Almostakbal. Retrieved from

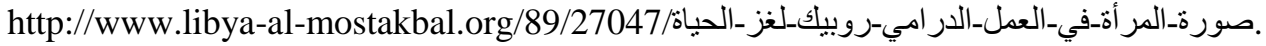

Al-Haddad, F. (2010). Critical Studies in Libyan Narrative. Benghazi: Dar AlkutubAlwataniya.

${ }^{5}$ This short story was provided to the researcher by the author himself via email. 
Almaghhour, A. (2012, March). Tea Cup.Libya Almostakbal. Retrieved from http://www.libya-al-mostakbal.org/news/clicked/20829

Almoghrabi, L. (2017, May). The Soup Pot.Libya Almostakbal. Retrieved from

http://www.libya-al-mostakbal.org/89/24435/\%D9\%84\%D9\%8A\%D9\%84\%D9\%8A-

$\% \mathrm{D} 8 \% \mathrm{~A} 7 \% \mathrm{D} 9 \% 84 \% \mathrm{D} 9 \% 85 \% \mathrm{D} 8 \% \mathrm{BA} \% \mathrm{D} 8 \% \mathrm{~B} 1 \% \mathrm{D} 8 \% \mathrm{~A} 8 \% \mathrm{D} 9 \% 8 \mathrm{~A}-$

$\% \mathrm{D} 8 \% \mathrm{~B} 7 \% \mathrm{D} 9 \% 86 \% \mathrm{D} 8 \% \mathrm{AC} \% \mathrm{D} 8 \% \mathrm{~B} 1 \% \mathrm{D} 8 \% \mathrm{~A} 9-$

\%D8\%A7\%D9\%84\%D8\%B4\%D8\%B1\%D8\%A8\%D8\%A9-\%D9\%82\%D8\%B5\%D8\%A9-

\%D9\%82\%D8\%B5\%D9\%8A\%D8\%B1\%D8\%A9.html

Almoghrabi, L. (2017, July). Wrinkles.Libya Almostakbal. Retrieved from

http://www.libya-al-mostakbal.org/89/26853/\%D8\%AA\%D8\%AC\%D8\%A7\%D8\%B9\%D9\%8A\%D8\%AF-

\%D9\%82\%D8\%B5\%D8\%A9-\%D9\%84\%D9\%8A\%D9\%84\%D9\%8A-

\%D8\%A7\%D9\%84\%D9\%85\%D8\%BA\%D8\%B1\%D8\%A8\%D9\%8A.html

Bin Shatwan, N. (October, 2011). Ajaadda Salha.Sho`ounLibiya. Retrieved from https://shuoon.wordpress.com/2011/10/18/\%D8\%A7\%D9\%84\%D8\%AC\%D8\%AF\%D8\%A9-

\%D8\%B5\%D8\%A7\%D9\%84\%D8\%AD\%D8\%A9/

Carter, R \& Long, M.N. (1992).Teaching Literature. Hong Kong: Longman.

Chivvis, C. (2014).Toppling Qaddafi: Libya and the Limits of Liberal Intervention. New York: Cambridge University Press.

Chorin, E. (2008). Translating Libya: The Modern Libyan Short Story. London: Middle East Institute SOAS.

Chorin, E. (2012). Exit the Colonel: The Hidden History of the Libyan Revolution. New York: Public Affairs.

Elhaddad, S. (2017, July). Entrapment. Libya Almostakbal. Retrieved from http://www.libya-al-mostakbal.org/89/26358/\%D8\%B5\%D9\%84\%D8\%A7\%D8\%AD-

\%D8\%A7\%D9\%84\%D8\%AD\%D8\%AF\%D8\%A7\%D8\%AF-\%D9\%82\%D8\%B5\%D8\%B5-

\%D9\%82\%D8\%B5\%D9\%8A\%D8\%B1\%D8\%A9-\%D8\%AC\%D8\%AF\%D8\%A7.html

Elnaili, S. (2014). Adjectives of Colour in Libyan Short Stories: A Stylistic Analysis. In Arua E. A, Abioye, T, \&Ayoola, K (Eds), Language, Literature and Style in Africa, (pp.131-141). UK: Cambridge Scholars Publishing.

Fagih, A. (2008). The Libyan Short Story: A Research and Anthology. United States: Xlibiris Corporation.

Gheblawi, G. (2011). Libyan Literature: The Impact of Revolution. Minerva. Retrieved from http://www.minervanett.no/the-impact-of-revolution/

Hassan, A, Al-Sammerai, N, \&Bin Abdul Kadir, F. (2011).How Colors are Semantically Construct in the Arabic and English Culture: A Comparative Study.English Language Teaching 4 (3), 206-213.

He, G. (2009).English and Chinese Cultural Connotation of Color Words in Comparison.Asian Social Science 5(7), 160-163.

Khalifa, k. (2017, July). Baghdad... September 1984. Libya Almostakbal. Retrieved from http://www.libya-al-mostakbal.org/89/26714/\%D8\%A8\%D8\%BA\%D8\%AF\%D8\%A7\%D8\%AF\%D8\%B3\%D8\%A8\%D8\%AA\%D9\%85\%D8\%A8\%D8\%B1-1984-\%D9\%82\%D8\%B5\%D8\%A9\%D9\%85\%D8\%AD\%D8\%A8\%D9\%88\%D8\%A8\%D8\%A9-

\%D8\%AE\%D9\%84\%D9\%8A\%D9\%81\%D8\%A9.html

Pargeter, A. (2012). Libya: The Rise and Fall of Qaddafi. New Haven \& London: Yale University Press.

St. John, R. B. (2008).Libya: From Colony to Independence. Oxford: Oneworld Publications.

Van Dijk, T. (2001). Critical Discourse Analysis. In Schiffin, D, Tannen, D, \& Hamilton, H (Eds), The Handbook of Discourse Analysis, (pp.352-371) USA: Blackwell Publishing.

Vandewalle, D. (2012). A History of Modern Libya. New York: Cambridge University Press.

Younis, G. (2017, June). Assassination. Libya Almostakbal. Retrieved from

http://www.libya-al-mostakbal.org/89/25985/\%D8\%BA\%D8\%A7\%D9\%84\%D9\%8A\%D8\%A9$\% \mathrm{D} 9 \% 8 \mathrm{~A} \% \mathrm{D} 9 \% 88 \% \mathrm{D} 9 \% 86 \% \mathrm{D} 8 \% \mathrm{~B} 3-\% \mathrm{D} 9 \% 82 \% \mathrm{D} 8 \% \mathrm{~B} 5 \% \mathrm{D} 8 \% \mathrm{~B} 5-$ \%D9\%82\%D8\%B5\%D9\%8A\%D8\%B1\%D8\%A9-\%D8\%AC\%D8\%AF\%D8\%A7-1.html

Younis, G. (2017, June). My Wife is an Ominous Crow. Libya Almostakbal. Retrieved from

http://www.libya-al-mostakbal.org/89/25094/\%D8\%BA-\%D8\%B1\%D8\%A7\%D8\%A8-\%D8\%A7\%D9\%84\%D8\%A8\%D9\%8A-\%D9\%86-\%D8\%B2\%D9\%88\%D8\%AC\%D8\%AA\%D9\%8A-\%D9\%82\%D8\%B5\%D8\%A9\%D8\%BA\%D8\%A7\%D9\%84\%D9\%8A\%D8\%A9-\%D9\%8A\%D9\%88\%D9\%86\%D8\%B3.html

Younis, G. (2017, June). The Pigeons are not for Sale. Libya Almostakbal. Retrieved from http://www.libya-al-mostakbal.org/89/24905/\%D8\%A7\%D9\%84\%D8\%AD\%D9\%85\%D8\%A7\%D9\%85\%D9\%84\%D9\%8A\%D8\%B3-\%D9\%84\%D9\%84\%D8\%A8\%D9\%8A\%D8\%B9-\%D9\%82\%D8\%B5\%D8\%A9\%D8\%BA\%D8\%A7\%D9\%84\%D9\%8A\%D8\%A9-\%D9\%8A\%D9\%88\%D9\%86\%D8\%B3.html 